\title{
OFICINAS INTERDISCIPLINARES REMOTAS: O Ensino de Ciências para Pessoas com Transtorno do Espectro Autista e a Busca pela Inclusão
}

\author{
Gisele Soares Lemos Shaw ${ }^{1}$ \\ Letícia Maria Oliveira²
}

\begin{abstract}
RESUMO
A pandemia de Covid-19 gerou a busca por novas formas de ensinar e aprender, o que ocorreu, inclusive, em cursos de formação de professores nas universidades. Tendo em vista propiciar formação inclusiva a 13 licenciandos em ciências da natureza, objetivou-se relatar e refletir sobre experiências de oficinas pedagógicas interdisciplinares e inclusivas para estudantes autistas e não autistas, realizadas de forma remota, e suas contribuições a mudanças nas percepções de autismo desses estudantes de Licenciatura. Essas oficinas ocorreram no âmbito da disciplina acadêmica Núcleo Temático Inclusivo no Ensino de Ciências, que possui caráter de ensino, pesquisa e extensão. Os dados foram coletados por materiais produzidos por esses estudantes, observação e questionários. Os mesmos foram analisados por análise de conteúdo. Foi observado que esses licenciandos possuíam conhecimentos sobre o Transtorno do Espectro Autista (TEA) e, apesar de surgirem ideias estereotipadas sobre pessoas com TEA, verificou-se ampliação de suas percepções, exceto em dois casos.
\end{abstract}

Palavras-chave: Autismo; ciências; ensino; licenciatura.

REMOTE INTERDISCIPLINARY WORKSHOPS:

TEACHING SCIENCE TO PEOPLE WITH AUTISM SPECTRUM DISORDER AND THE SEARCH FOR INCLUSION

\section{ABSTRACT}

The Covid-19 pandemic has generated new ways of teaching and learning, which has even occurred in teacher training courses at universities. In order to provide inclusive training for thirteen undergraduate students in the natural sciences, the aim was to report and reflect on experiences of interdisciplinary and inclusive pedagogical workshops for autistic and non-autistic students, carried out remotely and their contributions to changing perceptions of autism in these undergraduate students. These workshops took place within the scope of the academic subject Thematic Core Inclusive in Science Teaching, which has a teaching, research and extension character. Data were collected using materials produced by these students, observation and questionnaires. They were analyzed by content analysis. It was observed that these graduates had knowledge about Autistic Spectrum Disorder (ASD) and, despite stereotyped ideas about people with ASD, there was an increase in their perceptions, except in two cases.

Keywords: Autism; science; teaching; graduation.

RECEBIDO EM: 15/6/2021

ACEITO EM: 4/11/2021

\footnotetext{
1 Autora correspondente. Universidade Federal do Vale do São Francisco - Univasf. Av. José de Sá Maniçoba, s/n - Centro. Petrolina/PE, Brasil. CEP 56304-205. http://lattes.cnpq.br/9195578929388801. https://orcid.org/0000-0001-5926-2679. giseleshaw@hotmail.com

2 Universidade Federal do Vale do São Francisco - Univasf. Petrolina/PE, Brasil. http://lattes.cnpq.br/9272870213276367. https://orcid. org/0000-0003-4795-2001.
} 


\section{INTRODUÇÃO}

A pandemia da Covid-19 gerou a busca por novas formas de ensinar e aprender no âmbito do isolamento social, e isso ocorreu, inclusive, na formação inicial de professores em universidades brasileiras. Nesse cenário, professores formadores passaram a contar com a exploração de tecnologias digitais e a experimentação de novas práticas pedagógicas, inclusive no que se refere à formação de licenciandos para inclusão de pessoas com Transtorno do Espectro Autista (TEA) em escolas regulares, campo em que há carência de estudos (OLIVEIRA; ANGELO; STREIECHEN, 2020, RAVET, 2017, SANTOS; LEÃO; AGAPITO, 2018).

Entendendo a importância de refletir acerca da formação de estudantes de Ensino Superior para inclusão em tempos de pandemia, objetivou-se relatar a experiência de realização de oficinas pedagógicas interdisciplinares que foram trabalhadas com crianças e jovens autistas e não autistas, e avaliar o impacto das mesmas na ampliação de percepções de 13 licenciandos em ciências da natureza. Essas oficinas pedagógicas foram desenvolvidas no âmbito de disciplina curricular do curso de Licenciatura em Ciências da Natureza da Universidade Federal do Vale do São Francisco (Univasf), no Campus de Senhor do Bonfim, Bahia. A disciplina, nomeada Núcleo Temático Inclusivo no Ensino de Ciências, possui caráter de ensino, pesquisa e extensão, sendo voltada à formação de licenciandos para inclusão escolar de pessoas com deficiência. Nesse caso, apresenta-se trajetória de equipe, formada por 3 professores formadores e 13 licenciandos, que trabalhou com a educação de crianças e jovens com TEA, analisando-se as percepções desses estudantes de Licenciatura.

Os dados foram produzidos por meio de produções dos licenciandos, observação participante e questionário aplicado com os mesmos no início e ao final da disciplina. Foi realizada análise de conteúdo, que possibilitou a descrição das atividades da referida equipe no processo de formação dos estudantes de Licenciatura, além do possível alargamento de suas percepções acerca do autismo.

\section{PRESSUPOSTOS TEÓRICOS}

Para falar de ensino inclusivo para pessoas autistas, sejam elas crianças, jovens ou adultos, é preciso conhecer esse universo, por vezes tão mal compreendido. A palavra autista reúne em si algo peculiar ao comportamento das pessoas com Transtorno do Espectro do Autismo (TEA). Gomes (2007) remete etimologicamente ao termo, quando "auto" representa "em si mesmo" e "ismo", "voltado para". Temos, assim, o termo "voltado a si mesmo", traduzindo o significado da palavra "autismo". O entendimento de características do transtorno no decorrer de décadas, desde o século 20, mostrou que essa etimologia destoa da realidade.

O termo "autismo" decorre de uma definição mais específica, denominada TEA, que se trata de um grupo de distúrbios do desenvolvimento neurológico de início precoce, e que se caracteriza por comprometimentos das habilidades sociais e de comunicação, além de comportamentos estereotipados (APA, 2013). Esses comprometimentos, junto a outras manifestações e, por vezes, comorbidades associadas, promovem a ideia de que "pessoas autistas não queiram socializar, sendo voltadas a si mesmas". 
Embora haja um conjunto de características principais, alguns comportamentos de pacientes com TEA podem variar muito, por isso o autismo é enquadrado num espectro, por conta dessa heterogeneidade do transtorno. As manifestações dessa condição variam de indivíduo para indivíduo, abrangendo características mais específicas, tais como dificuldades de entender pensamentos e intenções alheias (WILLIANS; WRIGHT, 2008) e dificuldades de reciprocidade social (ROGERS; DAWSON, 2014). Algumas comorbidades podem se associar ao TEA, gerando uma diversidade de condições, desde indivíduos com deficiência intelectual (DI) grave, com baixo desempenho em habilidades comportamentais adaptativas, até indivíduos com quociente de inteligência (QI) considerado padrão, que levam uma vida de forma independente. Pode haver outras comorbidades além dessas, tais como hiperatividade, distúrbios de sono e gastrintestinais e epilepsia.(ZAFEIRIOU; VERVERI; VARGIAMI, 2007).

Segundo Wing (1991), as pessoas autistas possuem três grandes grupos de perturbações, as quais se manifestam em três diferentes áreas de domínio, sendo elas: a Área Social, a da Linguagem e Comunicação e a do Comportamento e Pensamento. A criança com qualquer comportamento referente ao transtorno do espectro autista possui uma forma diferenciada de ver o mundo, o que a leva a ter uma forma também distinta de interagir com as pessoas, bem como com todo o contexto onde está inserida. Dillon, Underwood e Freemantle (2014) destacaram que pessoas autistas desejam interagir com outras pessoas, mas possuem dificuldades em fazê-lo. Esse fato aponta para a imprescibilidade de haver pessoas que medeiem esse processo de socialização, cujas dificuldades podem comprometer a inclusão escolar de pessoas com TEA (DILLON; UNDERWOOD; FREEMANTLE, 2014).

Apesar, entretanto, de ainda vivermos em uma sociedade com padrões pré-estabelecidos, onde qualquer pessoa que apresente um comportamento não condizente a eles corre o risco de ser excluída, nos últimos anos percebe-se que tem se buscado uma melhor compreensão a respeito do TEA e o desenvolvimento de novas metodologias e práticas de atendimento ao autista, seja no campo da medicina, da psicologia ou da educação (MATIAS; PROBST, 2018).

Com respeito ao ensino e à inclusão, nos últimos anos tem se vivenciado mudanças significativas sobre conhecimentos acerca do autismo, bem como avanços, embora tímidos, no desenvolvimento de estratégias para o ensino de autistas. Dois marcos importantes para inclusão de crianças com autismo foram, respectivamente, a Portaria 1.635/2002, que prescreve a pessoas com deficiência mental e autismo assistência por intermédio de equipe multiprofissional e multidisciplinar, e a Lei 12.764/2012, que institui a Política Nacional de Proteção dos Direitos da Pessoa com Transtorno do Espectro Autista.

Ponce e Abrão (2019) pesquisaram quatro professoras atuantes em classes regulares que possuem estudantes autistas do município de Assis, Estado de São Paulo. Por meio de entrevistas semiestruturadas, os autores afirmaram que, embora a busca pela inclusão de crianças com autismo no Brasil tenha se tornado realidade, as especificidades do autismo colocam em destaque algumas idiossincrasias e requerem um olhar mais apurado do professor sobre o tema. Segundo os autores, há angústia das profissionais investigadas quanto à falta de formação para ajudar na inclusão de pessoas com 
TEA. Elas ainda destacaram que o maior problema da inclusão não diz respeito à impossibilidade de manter o aluno com autismo na escola regular, e, sim, a necessidade de os professores estarem preparados para recebê-los: "É fundamental que o fazer educativo esteja pautado na singularidade do aluno, de modo que o professor respeite suas dificuldades [...], o professor deve ter um olhar que veja potenciais a serem desenvolvidos" (PONCE; ABRÃO, 2019, p. 354).

Estudo de Souza et al. (2019) investigou a efetividade de oficinas pedagógicas sobre TEA realizadas com 75 pessoas - pais e cuidadores, profissionais da educação e profissionais da saúde. Os dados foram coletados por meio de questionários pré e pós-teste com cada grupo de participantes. Como resultados, observou-se aumento no número de acertos dos participantes em questões sobre identificação de TEA e tratamento da condição.

Outro estudo, de Oliveira, Angelo e Streiechen (2020), realizado com 22 acadêmicos dos cursos de Letras-Espanhol e Letras-Inglês, de uma universidade pública do interior do Paraná, sondou conhecimentos sobre autismo e acerca do processo de escolarização de pessoas com TEA. Os dados foram coletados por questionários e indicaram que os estudantes estão recebendo poucas informações sobre autismo, e que parte dos conhecimentos deles provêm de estudos individuais.

Observa-se, assim, que o ensino para pessoas com quaisquer dos transtornos que englobam o espectro autista requer atenção e preparo de quem o executa, além de características importantes, tais como envolvimento, paciência, criatividade e dinamismo, o que igualmente se aplica ao ensino de qualquer indivíduo. Esses foram, portanto, fatores que conduziram à elaboração e à execução de oficinas interdisciplinares, que partiram de temáticas relativas às ciências para crianças e jovens autistas e não autistas em conjunto. A realização dessas oficinas foi parte de um componente curricular, denominado Núcleo Temático, que tratou do tema "inclusão". Nessa prática de elaboração e execução, os discentes, bem como os docentes que os orientaram, puderam vivenciar a experiência de levar temas científicos a crianças e jovens autistas e, com isso, confirmar ou reconstruir suas percepções sobre autismo.

\section{METODOLOGIA}

Buscou-se relatar e refletir sobre experiência de realização de oficinas pedagógicas interdisciplinares que foram trabalhadas com crianças e jovens autistas e não autistas, e avaliar o impacto das mesmas na ampliação de percepções de 13 licenciandos em ciências da natureza. A pesquisa é considerada, conforme Moreira (2011), como estudo de caso educativo. Dado seu objeto de pesquisa de natureza difícil de mensurar, que foram as percepções de estudantes de Licenciatura, e considerando o desenvolvimento da mesma, sua natureza é qualitativa.

As oficinas pedagógicas ocorreram no âmbito da disciplina Núcleo Temático Inclusivo no Ensino de Ciências (NT), ofertada pelo Colegiado de Ciências da Natureza da Univasf, no Campus de Senhor do Bonfim, Bahia, Brasil. Esse NT consiste em disciplina curricular de curso de Graduação de Licenciatura em Ciências da Natureza, possui 120 horas de duração e tem caráter de ensino, pesquisa e extensão, distribuídas em: $25 \%$ dessa carga horária para reuniões de orientação e/ou avaliação e 75\% dela para encon- 
tros remotos, práticas de ensino, pesquisa e extensão (conforme Resolução 01/2014 da Câmara de Ensino da Univasf). Todo estudante, de qualquer curso de Graduação dessa universidade, tem de participar de, pelo menos, um núcleo temático.

A proposta do Núcleo Temático Inclusivo no Ensino de Ciências busca auxiliar na formação inclusiva dos estudantes por meio do acompanhamento de professores orientadores das atividades de ensino, pesquisa e extensão na educação em ciências. O NT em questão atua na formação inclusiva junto as seguintes linhas de estudo: a) Ensino de ciências para crianças autistas: superando desafios; b) Ensino de ciências em uma perspectiva inclusiva; e c) Ensino de ciências investigativo e inclusivo para os anos finais do Ensino Fundamental.

Cada grupo de cinco estudantes matriculados é orientado por um professor formador. Durante o semestre 2020.1, de caráter complementar, devido à pandemia da Covid-19, a equipe Ensino de Ciências Para Crianças Autistas foi formada por 3 professores formadores e 15 licenciandos, que desenvolveram suas atividades de ensino, pesquisa e extensão com base na inclusão de pessoas autistas no ensino, buscando promover práticas interdisciplinares, conforme mostra a Figura 1. Foi possível, contudo, somente investigar a formação de 13 desses estudantes, que participaram de todas atividades da disciplina.

Figura 1 - Percurso da equipe Ensino de Ciências Para Crianças Autistas

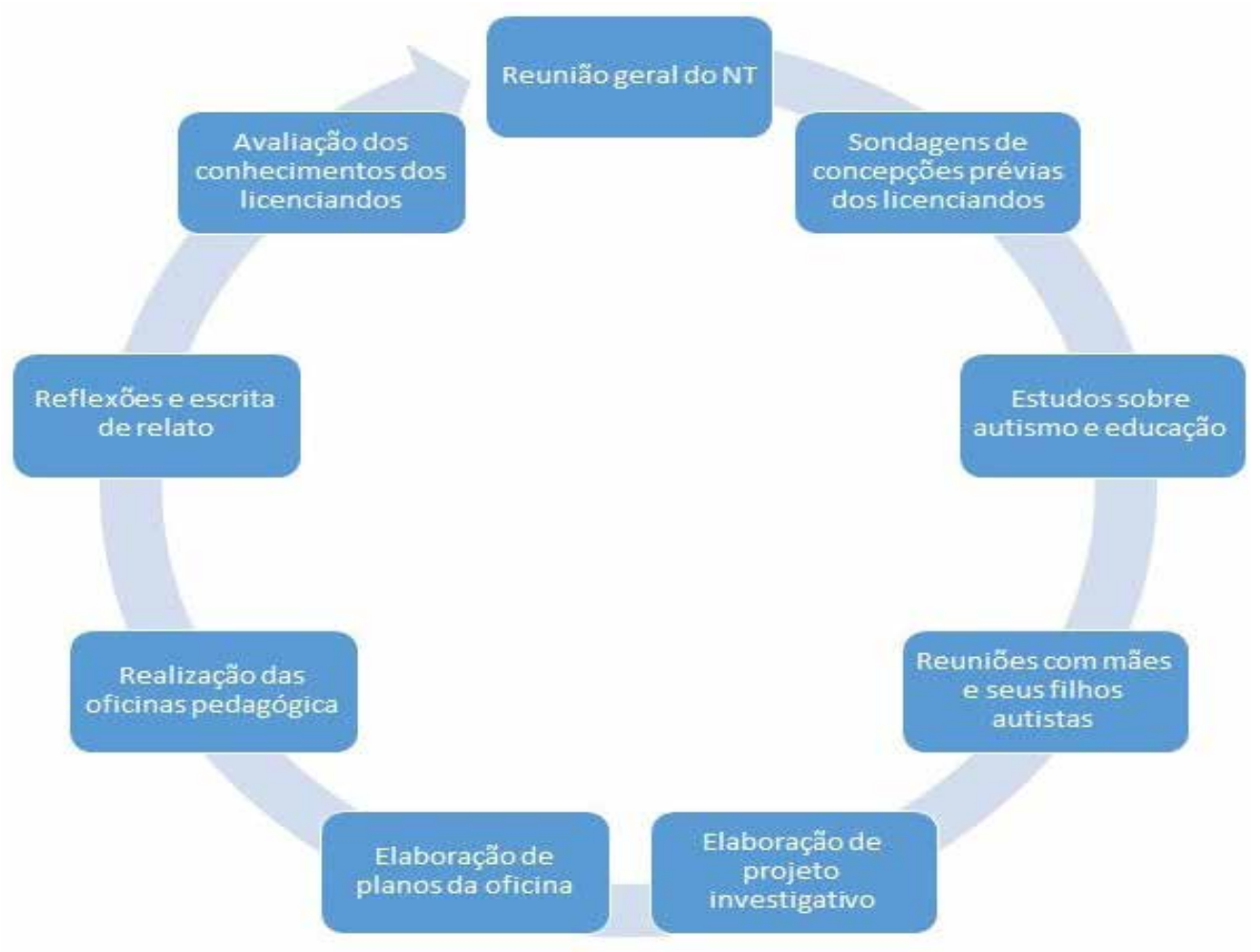

Fonte: SHAW, 20213.

O artigo Núcleo temático inclusivo para construção de conhecimentos de licenciandos em ciências da natureza sobre o transtorno do espectro autista foi publicado na Revista Atos em Educação (SHAW, 2021). Disponível em https://bu.furb.br/ojs/index.php/atosdepesquisa/article/view/9037. Acesso em: 9 nov. 2021. 
A investigação, que envolveu a educação inclusiva de autistas e a formação interdisciplinar e inclusiva de estudantes de Licenciatura, compõe o "Projeto Ensinar Ciências a Todos: sequências didáticas interdisciplinares e inclusivas", que seguiu critérios de ética na pesquisa do Conselho Nacional de Saúde, conforme Resolução no 510/2016 (BRASIL, 2016), tendo aprovação do Comitê de Ética da Pesquisa da Univasf (CEP), registrado sob o CAAE 26354319.4.0000.5196. A experiência relatada neste artigo foi realizada como experiência piloto desse projeto, financiado pelo Programa Ciência na Escola, que busca melhorar o ensino de ciência em escolas públicas brasileiras ${ }^{4}$.

Os dados deste estudo foram produzidos por meio de produções dos licenciandos (seus projetos de investigação, planos de oficinas e relatos escritos da experiência), observação participante e questionário aplicado com os mesmos no início e ao final da disciplina. As questões dos questionário foram abertas e estão dispostas no Quadro a seguir.

Quadro 1 - Questões dos questionários pré e pós-teste

\begin{tabular}{|l|}
\hline \multicolumn{1}{|c|}{ Questões } \\
\hline Questão 1) Como você define o autismo (Transtorno do Espectro Autista)? \\
\hline $\begin{array}{l}\text { Questão 2) Cite características que podem auxiliar na identificação da pessoa com Transtorno } \\
\text { do Espectro Autista. }\end{array}$ \\
\hline Questão 3) Você conhece pessoa(s) autista(s)? Comente sua relação com ela(s). \\
\hline $\begin{array}{l}\text { Questão 4) Como você acredita que deve ser realizada a inclusão escolar de pessoas com } \\
\text { Transtorno do Espectro Autista? }\end{array}$ \\
\hline $\begin{array}{l}\text { Questão 5) Explique como pensa que devem ser ensinados conteúdos de ciências para pessoas } \\
\text { autistas nas escolas regulares. }\end{array}$ \\
\hline Questão 6) Quais são os maiores desafios das pessoas autistas (com TEA) e de seus familiares? \\
\hline
\end{tabular}

Fonte: Arquivo dos autores, 2021.

Este artigo buscou atender ao objetivo geral apresentado a partir das seguintes perguntas de pesquisa: 1 - Como se deu o desenvolvimento de atividades da Equipe Educação Para Autistas no decorrer do núcleo temático? 2 - Houve ampliação nas percepções dos estudantes de Licenciatura participantes no processo? Para isso, foram discutidos dados referentes às questões um e dois dos questionários, além daqueles produzidos pelos demais instrumentos de coleta. Esses dados foram organizados em arquivo de texto, impresso e avaliado segundo análise de conteúdo (BARDIN, 1977, MORAES, 1999). Foram efetivadas diversas leituras buscando responder às referidas questões de estudo. Essas respostas foram destacadas e organizadas em duas categorias: Relato da experiência e Percepções dos licenciandos sobre autismo. As categorias foram descritas e interpretadas à luz de literatura elencada, conforme observa-se no tópico seguinte.

O Programa Ciência na Escola foi criado por meio de parceria entre Ministério da Ciência, Tecnologia, Inovações e Comunicações (MCTIC), Ministério da Educação (MEC), Conselho Nacional de Desenvolvimento Científico e Tecnológico (CNPq) e Coordenação de Aperfeiçoamento de Pessoal de Nível Superior (Capes). 


\section{RESULTADOS E DISCUSSÕES}

O relato das atividades da Equipe Educação Para Autistas e o resultado da sondagem acerca de possíveis modificações nas percepções dos licenciandos sobre autismo retrataram parte da complexidade do trabalho educativo desse grupo na disciplina Núcleo Temático Inclusivo no Ensino de Ciências. Foram articuladas atividades de ensino, pesquisa e extensão em meio aos desafios do ensino remoto voltadas à educação inclusiva e interdisciplinar de pessoas autistas.

O ensino foi circunscrito em busca da formação inclusiva e interdisciplinar dos estudantes de licenciatura envolvidos, que construíram conhecimentos e habilidades para realizar uma educação que não se voltasse somente a pessoas neurotípicas, mas que observasse indivíduos com TEA. As oficinas promovidas por esses licenciandos e seus orientadores ofereceram a crianças e jovens autistas e não autistas a oportunidade de aprender ciências de modo articulado a outras disciplinas, e esse trabalho foi focado em atender às especificidades de cada participante, conforme orientaram Ponce e Abrão (2019).

Nessa experiência, a dimensão pesquisa se deu de duas formas - pedagógica e científica. Primeiro, buscou-se auxiliar na formação de estudantes de Licenciatura a partir da proposição de leituras, dinâmicas, análises, discussões, planejamentos e situações que podem possibilitar o exercício de diversos conhecimentos e habilidades: da reflexão, da criticidade, do planejamento, da produção, da participação em situações didático-pedagógicas, da avaliação de seu próprio trabalho, da escuta de ideias e estratégias de colegas, da elaboração de suas próprias estratégias, do compartilhamento de suas próprias ideias, da reconstrução de conceitos, da dinamicidade do trabalho docente, da necessidade de tomar decisões e revisá-las. Esse percurso possibilitou que esses estudantes exercitassem a postura de professores pesquisadores por meio da reflexão na ação e sobre a ação. Além disso, a experiência do núcleo temático permitiu aos três professores formadores compartilhar o trabalho em equipe, a troca de conhecimentos, o aprendizado mútuo, e, também, investigar, cientificamente, o processo formativo de seus licenciandos.

A seguir, apresentou-se a trajetória da equipe Ensino de Ciências Para Crianças Autistas, pontuando as oficinas pedagógicas desenvolvidas pelos estudantes participantes e, ao final, identificando mudanças, ou não, em suas percepções sobre o autismo.

\section{Relato da Experiência}

O trabalho da equipe Ensino de Ciências Para Crianças Autistas foi realizado de modo remoto, por meio de atividades síncronas e assíncronas. Essas atividades foram apoiadas por ferramentas digitais, tais como plataforma AVA, Google Meet, Sistema de webconferência RNP, WhatsApp, Google Formulários, Jamboard, Mentimeter, Pro Word Cloud e vídeos do Youtube.

Algumas atividades foram gerais, realizadas com as demais equipes do núcleo temático: três reuniões, sendo duas delas no início e outra ao final da disciplina. As demais atividades foram realizadas pelas equipes segundo seu planejamento. Assim, o primeiro contato dos estudantes de Licenciatura com a disciplina ocorreu na primeira 
reunião geral, quando houve realização de duas palestras - uma delas sobre modelos de inclusão e outra sobre tecnologias assistivas. Essas palestras trouxeram abordagem mais geral, de modo a gerar reflexões sobre como cada um pensa acerca da deficiência, se baseados numa abordagem médica, social ou pós-social, e sobre como utilizar tecnologias assistivas no ensino voltado a pessoas com deficiência.

Na segunda reunião geral também houve palestra sobre inclusão escolar de pessoas com deficiências, além de terem sido definidas as equipes de trabalho, quando se conheceu os 15 estudantes que trabalhariam, a partir de então, com educação para inclusão de autistas.

A primeira atividade específica dessa equipe foi responder a questionário de sondagem sobre concepções de autismo, experiência com pessoa com TEA, percepções de inclusão escolar e possíveis dificuldades vivenciadas por elas. Essa atividade foi efetivada pelos 15 licenciados matriculados no NT, em formulário do Google, cujo link foi disponibilizado em curso criado na plataforma AVA da Univasf, definido como espaço de realização de atividades assíncronas. Nesse curso foram alocados o Plano da disciplina, cronograma, quadro de avisos e outros recursos didático-pedagógicos, tais como fóruns, leituras, postagens e trabalhos, locais de criação colaborativa de textos, entre outros.

Nas webconferências iniciais, ocorridas nas primeiras etapas da disciplina, foram realizados estudos sobre autismo, inclusão e aprendizagem segundo Vigotsky (2007). Nesses encontros, além de dinâmica feita por meio de desenho para sondagem de significados do TEA pelos participantes, houve formação de nuvens de palavras, com características do transtorno, além da análise de vídeos com trechos de filmes e séries, abordando diferentes modos de ser e de viver de pessoas autistas. Nesse processo, muitos estudantes e, inclusive, dois professores, identificaram traços de autismo em si mesmos. Um deles, mais tarde, buscou avaliação neuropsicológica que apontou a presença do transtorno, sendo diagnosticado com TEA de grau leve, altas habilidades e Transtorno de Déficit de Atenção (TDA). Essa evidência indicou que a experiência formativa atingiu também os docentes formadores de futuros professores, o que se constitui bom indicativo, dado que, segundo Ponce e Abrão (2019), "o maior problema da inclusão não diz respeito à impossibilidade de manter o aluno com autismo na escola regular e sim a necessidade de os professores estarem preparados para recebê-los" (p. 353).

Como atividades assíncronas, foram realizadas leituras e discussões em fóruns dispostos na plataforma AVA, além de disponibilizados vídeos do Youtube sobre autismo e inclusão.

Estudos apontaram a importância da formação do professor ou, nesse caso, de futuros professores, para inclusão de pessoas autistas em escolas regulares (MATIAS; PROBST, 2018, OLIVEIRA; ANGELO; STREIECHEN, 2020, PONCE; ABRÃO, 2019), ainda que cursos de formação de Licenciatura não estejam trazendo informações suficientes acerca da inclusão de pessoas autistas ou de indivíduos com outras deficiências (OLIVEIRA; ANGELO; STREIECHEN, 2020). Por isso, não são encontradas muitas produções científicas da formação inclusiva em âmbito de Licenciaturas e de cursos de formação continuada de professores (OLIVEIRA; ANGELO; STREIECHEN, 2020, RAVET, 2017, SANTOS; LEÃO; AGAPITO, 2018). 
Após estudos e reflexões sobre o TEA, aprendizagem e inclusão escolar, dividiu-se a equipe em cinco grupos de estudantes, que iniciaram o planejamento de projetos de investigação. Foram dadas orientações acerca da construção dessa proposta, fornecido modelo base e apresentados critérios avaliativos. Esses projetos planejaram o estudo das aprendizagens de pessoas autistas (crianças ou jovens) por meio de oficinas pedagógicas interdisciplinares. Nesse momento, cada grupo pensou na temática de sua oficina, conteúdos a ser trabalhados e possíveis metodologias a serem utilizadas. Então, com base nesses aspectos, foram criados projetos abrangendo: problemas de pesquisa, questões de pesquisa, objetivos geral e específicos, metodologia, fundamentação teórica e cronograma de execução. Também foram organizados instrumentos de coleta de dados, validados pelos orientadores. A produção dos projetos foi colaborativa, pois todos os grupos dispuseram seu projeto em arquivo de texto que foi compartilhado com todos os participantes e alocado na plataforma AVA.

Concomitantemente, pais de pessoas autistas foram contatados por intermédio de grupos de WhatsApp de associações de autistas e seus familiares do município de Senhor do Bonfim e região circunvizinha. Os cuidadores que aceitaram que seus filhos participassem do estudo e oficinas tiveram informações sobre ambos e assinaram Termo de Livre Consentimento Esclarecido, seguindo critérios éticos.

Em seguida, os grupos e orientadores reuniram-se com pessoas autistas participantes e seus pais por meio de webconferências, quando foram compartilhados interesses, habilidades, dificuldades de cada participante e características do transtorno apresentadas por eles. Ainda, foram observadas perspectivas de pais e filhos sobre o que gostariam que a equipe realizasse.

A partir desses momentos foram construídos perfis das pessoas autistas participantes, de modo a possibilitar planejamento personalizado de cada oficina pedagógica. Esses perfis foram produzidos em texto colaborativo, na plataforma AVA, e os perfis finais também foram postados nesse espaço. De acordo com Ponce e Abrão (2019), é preciso que o processo educativo de pessoas autistas seja pautado em singularidades, de modo que o professor trabalhe em torno das potencialidades desses sujeitos ao invés de se prenderem a suas dificuldades.

Assim, a partir do projeto de pesquisa e perfis de participantes, foram produzidos planos didáticos de cada oficina pedagógica, observando, sempre, aspectos gerais de elaboração de plano de aula - tema, duração, conteúdos, metodologia, avaliação e recursos; além de aspectos complementares relativos à busca pela interdisciplinaridade: disciplinas curriculares envolvidas, objetivos ligados às mesmas e possibilidades de articulações interdisciplinares. As orientações desse planejamento se deram por webconferência e pela correção de arquivo compartilhado e disponibilizado na plataforma AVA.

Nesse processo, cada equipe apresentou seus planos aos colegas e professores, que discutiram e contribuíram com cada produção. Esse investimento em situações de produção colaborativa se deu pela percepção dos professores de que a construção do conhecimento ocorre tanto por uma mobilização interna, envolvendo empenho pessoal, quanto por trocas estabelecidas mediante a interação social e o contato com recursos didático-pedagógicos e experiências vivenciadas. 
O percurso da equipe Ensino de ciências para crianças autistas foi ilustrado no Quadro 2, que apresenta cada etapa de trabalho e as atividades desenvolvidas, discriminando recursos tecnológicos utilizados e se essas atividades foram síncronas ou assíncronas.

Quadro 2 - Atividades desenvolvidas pela equipe Ensino de Ciências Para Crianças Autistas

\begin{tabular}{|c|c|c|}
\hline Etapas & C.H. & Atividade realizada \\
\hline 1a Reunião geral & $2 \mathrm{~h}$ & Palestra sobre Modelos de deficiência atividade síncrona. \\
\hline 2a Reunião geral & $2 \mathrm{~h}$ & $\begin{array}{l}\text { Palestra sobre Inclusão escolar de pessoas com deficiência e } \\
\text { divisão das equipes por webconferência - atividade síncrona. }\end{array}$ \\
\hline $\begin{array}{l}\text { Questionário de } \\
\text { sondagem }\end{array}$ & $2 \mathrm{~h}$ & $\begin{array}{l}\text { Questionário inicial de sondagem de conhecimentos dos } \\
\text { estudantes pelo Google Forms - atividade assíncrona. }\end{array}$ \\
\hline $\begin{array}{l}\text { Estudo sobre } \\
\text { inclusão escolar }\end{array}$ & $2 \mathrm{~h}$ & $\begin{array}{l}\text { Leitura e discussão de texto sobre Inclusão escolar de pessoas } \\
\text { autistas em fórum da plataforma AVA, vídeo no Youtube - } \\
\text { atividades assíncronas. }\end{array}$ \\
\hline $\begin{array}{l}\text { Encontro da equipe } \\
\text { e estudos }\end{array}$ & $2 \mathrm{~h}$ & $\begin{array}{l}\text { Diálogo sobre proposta, conhecimento dos participantes e } \\
\text { apresentação sobre TEA por webconferência - atividades } \\
\text { síncronas. }\end{array}$ \\
\hline Estudo sobre TEA & $2 \mathrm{~h}$ & $\begin{array}{l}\text { Leitura e discussão de capítulos de livro sobre autismo por fórum } \\
\text { na plataforma AVA - atividades assíncronas. }\end{array}$ \\
\hline $\begin{array}{l}\text { Estudo sobre } \\
\text { características do } \\
\text { transtorno }\end{array}$ & $2 \mathrm{~h}$ & $\begin{array}{l}\text { Apresentação dialogada sobre TEA, análise de cenas de filmes } \\
\text { e séries, montagem de nuvem de palavras no Word Cloud (do } \\
\text { Google) por webconferência, vídeos do Youtube - atividades } \\
\text { síncronas. }\end{array}$ \\
\hline $\begin{array}{l}\text { Estudo sobre } \\
\text { aprendizagem }\end{array}$ & $2 \mathrm{~h}$ & $\begin{array}{l}\text { Leitura e fichamento de texto sobre Aprendizagem e } \\
\text { desenvolvimento segundo Vigotsky (2007) na plataforma AVA - } \\
\text { atividades assíncronas. }\end{array}$ \\
\hline Encontro da equipe & $2 \mathrm{~h}$ & $\begin{array}{l}\text { Orientações para elaboração de projeto investigativo por } \\
\text { webconferência-atividade síncrona. }\end{array}$ \\
\hline $\begin{array}{c}\text { Contato inicial com } \\
\text { pais de autistas }\end{array}$ & $2 \mathrm{~h}$ & $\begin{array}{l}\text { Contato, via WhatsApp, com pais de crianças e jovens autistas - } \\
\text { atividade assíncrona. }\end{array}$ \\
\hline $\begin{array}{c}\text { Construção, } \\
\text { orientações e } \\
\text { entrega de projetos } \\
\end{array}$ & $11 \mathrm{~h}$ & $\begin{array}{l}\text { Escrita colaborativa de projeto investigativo por pequenos grupos, } \\
\text { orientações por fórum e entrega na plataforma AVA - atividade } \\
\text { assíncrona. }\end{array}$ \\
\hline $\begin{array}{c}\text { Reunião com pais } \\
\text { de autistas }\end{array}$ & $8 \mathrm{~h}$ & $\begin{array}{l}\text { Reunião, via webconferência, com pais e filhos para apresentar as } \\
\text { propostas de conhecer participantes - atividade síncrona. }\end{array}$ \\
\hline $\begin{array}{l}\text { Orientações de } \\
\text { planos de oficinas }\end{array}$ & $2 \mathrm{~h}$ & $\begin{array}{l}\text { Orientações para planejamento de plano didático da oficina } \\
\text { interdisciplinar por webconferência - atividade síncrona. }\end{array}$ \\
\hline Escrita colaborativa & $8 \mathrm{~h}$ & $\begin{array}{l}\text { Escrita colaborativa de plano didático da oficina por grupos em } \\
\text { espaço na plataforma AVA - atividade assíncrona. }\end{array}$ \\
\hline $\begin{array}{l}\text { Discussão, } \\
\text { orientação e } \\
\text { entrega de planos } \\
\text { de oficinas }\end{array}$ & $10 \mathrm{~h}$ & $\begin{array}{l}\text { Discussão de plano didático da oficina por pequenos grupos e } \\
\text { seus orientadores em fórum e entregues em espaço de envio na } \\
\text { plataforma AVA - atividades assíncronas. }\end{array}$ \\
\hline Encontro da equipe & $2 \mathrm{~h}$ & $\begin{array}{l}\text { Compartilhamento, reflexão e discussão dos projetos investigativos } \\
\text { e planos das oficinas produzidos por webconferência - atividade } \\
\text { síncrona. }\end{array}$ \\
\hline $\begin{array}{l}\text { Organização de } \\
\text { materiais das } \\
\text { oficinas }\end{array}$ & $5 \mathrm{~h}$ & $\begin{array}{l}\text { Elaboração de materiais didáticos e seleção de instrumentos } \\
\text { digitais a ser utilizados nas oficinas - atividade assíncrona. }\end{array}$ \\
\hline
\end{tabular}




\begin{tabular}{|c|c|l|}
\hline $\begin{array}{c}\text { Organização do } \\
\text { ambiente digital }\end{array}$ & $4 \mathrm{~h}$ & Preparação dos ambientes das oficinas - atividade assíncrona. \\
\hline $\begin{array}{c}\text { Ciclo de oficinas } \\
\text { Educação em } \\
\text { Ciências }\end{array}$ & $9 \mathrm{~h}$ & $\begin{array}{l}\text { Realização das oficinas pedagógicas oficinas - atividades síncronas } \\
\text { e assíncronas. }\end{array}$ \\
\hline $\begin{array}{c}\text { Orientações sobre } \\
\text { análise de dados }\end{array}$ & $2 \mathrm{~h}$ & $\begin{array}{l}\text { Orientações sobre análise de dados por webconferência - } \\
\text { atividade síncrona. }\end{array}$ \\
\hline $\begin{array}{c}\text { Reflexões e } \\
\text { análises }\end{array}$ & $15 \mathrm{~h}$ & $\begin{array}{l}\text { Reflexões sobre experiência e escrita de resultados em texto } \\
\text { colaborativo na plataforma AVA e análise de dados - atividades } \\
\text { assíncronas. }\end{array}$ \\
\hline $\begin{array}{c}\text { Orientações para } \\
\text { escrita de relato }\end{array}$ & $2 \mathrm{~h}$ & $\begin{array}{l}\text { Orientações para escrita de relato de experiência por } \\
\text { webconferência - atividade síncrona. }\end{array}$ \\
\hline $\begin{array}{c}\text { Escrita dos relatos } \\
\text { Organização da } \\
\text { apresentação }\end{array}$ & $10 \mathrm{~h}$ & $\begin{array}{l}\text { Escrita relato sobre experiência da oficina em espaço na plataforma } \\
\text { AVA-atividade assíncrona. }\end{array}$ \\
\hline $\begin{array}{c}\text { 3a Reunião geral do } \\
\text { núcleo temático }\end{array}$ & $8 \mathrm{~h}$ & $\begin{array}{l}\text { Elaboração de slides para apresentações das experiências das } \\
\text { oficinas e resultados do projeto - atividade assíncrona. }\end{array}$ \\
\hline Questionário final \\
atividade síncrona.
\end{tabular}

Após a elaboração dos planos das oficinas foram produzidos recursos didáticos, atividades e organizados os ambientes virtuais de aprendizagem. Cada oficina pedagógica foi realizada em nove horas, distribuídas em - seis horas de atividades síncronas e três horas de atividades assíncronas. Cada grupo intercalou as atividades assíncronas entre dois dias de atividades síncronas, feitas por meio de webconferências em Google Meet, com duração de três horas cada. Apresenta-se informações sobre essas oficinas no Quadro 3.

Quadro 3 - Oficinas desenvolvidas no pela equipe Ensino de Ciências para Crianças Autistas

\begin{tabular}{|c|c|c|c|c|}
\hline Nome & Participantes & Conteúdos & Disciplinas & Atividades realizadas \\
\hline $\begin{array}{c}\text { Corpo } \\
\text { humano e } \\
\text { saúde no } \\
\text { ensino de } \\
\text { ciências para } \\
\text { crianças } \\
\text { autistas }\end{array}$ & $\begin{array}{c}\text { Quatro crianças } \\
\text { autistas, entre } \\
10 \text { e } 12 \text { anos de } \\
\text { idade. }\end{array}$ & $\begin{array}{c}\text { Saúde do } \\
\text { corpo humano: } \\
\text { hábitos de } \\
\text { higiene e } \\
\text { alimentação } \\
\text { saudável }\end{array}$ & $\begin{array}{c}\text { Ciências, } \\
\text { Artes. }\end{array}$ & $\begin{array}{c}\text { Liveworksheets e jogos } \\
\text { educativos (no site Efuturo), } \\
\text { vídeos, webconferências, } \\
\text { experimento de higienização } \\
\text { das mãos, desenho de corpo } \\
\text { humano. }\end{array}$ \\
$\begin{array}{c}\text { Uma } \\
\text { proposta de } \\
\text { alimentação } \\
\text { saudável } \\
\text { no ensino } \\
\text { de ciências } \\
\text { para crianças } \\
\text { autistas e } \\
\text { não autistas }\end{array}$ & $\begin{array}{c}\text { Três crianças } \\
\text { autistas e uma } \\
\text { não autista, } \\
\text { entre } 4 \text { e 7 } \\
\text { anos. }\end{array}$ & $\begin{array}{c}\text { Alimentação } \\
\text { saudável, } \\
\text { grupos } \\
\text { alimentares, } \\
\text { proporção }\end{array}$ & $\begin{array}{c}\text { Matemâncias, } \\
\text { Artes }\end{array}$ & $\begin{array}{c}\text { Aplicação de questionário } \\
\text { pré e pós teste, observação, } \\
\text { aula dialogada por } \\
\text { webconferência, vídeos de } \\
\text { desenhos animados, caçada } \\
\text { ao tesouro, realização de } \\
\text { receitas culinárias, atividades } \\
\text { e desenhos feitos pelas } \\
\text { crianças. }\end{array}$ \\
\hline
\end{tabular}




\begin{tabular}{|c|c|c|c|c|}
\hline $\begin{array}{c}\text { Céu de dia e } \\
\text { a noite }\end{array}$ & $\begin{array}{l}\text { Duas crianças } \\
\text { autistas de } 2 \\
\text { e } 3 \text { anos de } \\
\text { idade. }\end{array}$ & $\begin{array}{l}\text { Números, } \\
\text { elementos do } \\
\text { céu de dia e de } \\
\text { noite, cores }\end{array}$ & $\begin{array}{l}\text { Ciências, } \\
\text { Matemática. }\end{array}$ & $\begin{array}{l}\text { Fotos e vídeos enviados por } \\
\text { WhatsApp, caixa do céu de } \\
\text { dia e caixa do céu de noite, } \\
\text { desenhos animados, pintura } \\
\text { e colagem, questionário pelo } \\
\text { Google Forms. }\end{array}$ \\
\hline $\begin{array}{c}\text { Uma } \\
\text { pequena } \\
\text { viagem pelos } \\
\text { planetas do } \\
\text { sistema solar }\end{array}$ & $\begin{array}{c}\text { Três jovens, } \\
13 \text { a } 16 \text { anos, } 2 \\
\text { autistas e } 1 \text { não } \\
\text { autista. }\end{array}$ & $\begin{array}{l}\text { Os planetas } \\
\text { do Sistema } \\
\text { Solar, suas } \\
\text { características, } \\
\text { espaçamento, } \\
\text { movimentos }\end{array}$ & $\begin{array}{c}\text { Ciências, } \\
\text { Matemática. }\end{array}$ & $\begin{array}{l}\text { Elaboração de desenho (pré- } \\
\text { teste), questionário (pós- } \\
\text { teste), vídeos, aplicativo Sky } \\
\text { Map, atividade lúdicas, quiz, } \\
\text { jogos. }\end{array}$ \\
\hline $\begin{array}{l}\text { Os astros } \\
\text { visíveis no } \\
\text { céu }\end{array}$ & $\begin{array}{c}\text { Cinco crianças } \\
\text { autistas entre } \\
5 \text { e } 6 \text { anos de } \\
\text { idade }\end{array}$ & $\begin{array}{l}\text { Períodos diários, } \\
\text { movimentos da } \\
\text { terra e unidades } \\
\text { de medida de } \\
\text { tempo: dia, } \\
\text { semana, mês e } \\
\text { ano. }\end{array}$ & $\begin{array}{l}\text { Ciências, } \\
\text { Matemática. }\end{array}$ & $\begin{array}{l}\text { Aplicação de questionário } \\
\text { de sondagem pelo Google } \\
\text { Forms, vídeos didáticos, } \\
\text { exposição com imagens } \\
\text { em slides, modelo } \\
\text { didático das fases da Lua, } \\
\text { ilustrações com objetos } \\
\text { domésticos (abóbora, maçã } \\
\text { e almofada), experimento } \\
\text { com lanterna e bola de } \\
\text { futebol, brincadeiras de } \\
\text { cunho educativo. }\end{array}$ \\
\hline
\end{tabular}

Fonte: Arquivos dos autores, 2021.

É importante destacar que os licenciandos planejaram suas oficinas a partir de conteúdos escolares previstos a serem trabalhados com crianças ou jovens, conforme as idades dos mesmo, segundo a Base Nacional Comum Curricular (BNCC) que norteia o ensino no Brasil (BRASIL, 2018). Além disso, as atividades foram voltadas a atender especificidades dos participantes não só relativas à idade, mas também a interesses, potencialidades e dificuldades, sem evidenciar essas últimas. Assim, as propostas tiveram diversificação metodológica, mas sem pautar esse aspecto como solucionador do processo de ensino, como explicaram Ponce e Abrão (2019). Segundo esses autores, a psicologização do ensino vigente no século 20 gerou a falsa ideia de que, com base em metodologias apropriadas, as crianças poderiam se ajustar em modelos ideais de indivíduos (PONCE; ABRÃO, 2019).

Todas as oficinas envolveram, pelo menos, duas disciplinas escolares, posto que Ciências e Matemática foram trabalhadas em quase todas elas, não aparecendo, somente, na oficina Corpo humano e saúde no ensino de ciências para crianças autistas, que envolveu Ciências e Artes. Ela foi realizada por meio de orientações dadas aos participantes, crianças entre 10 e 12 anos de idade, no Google Meet, levando-os a assistir vídeos, a participar de atividades no site Liveworksheets e jogos dispostos no site Efuturo. Além disso, essa equipe realizou experiência sobre higienização das mãos usando água, orégano e sabão. 
É importante destacar que alguns participantes dessa oficina também tinham deficiência intelectual, além de TEA, mas elas conseguiram realizar parte das tarefas com auxílios de suas mães. As crianças evidenciaram gostar dos vídeos e jogos, mas, no decorrer das atividades síncronas, muitas demonstraram impaciência por meio de seus comportamentos - levantando das cadeiras, girando e correndo. Alguns deles choravam, gritavam e/ou giravam após cerca de duas horas de atividades. Muitas tarefas da plataforma não foram respondidas, mas todos os participantes assistiram aos vídeos e interagiram com os jogos.

A oficina Uma proposta de alimentação saudável no ensino de ciências para crianças autistas e não autistas foi realizada com quatro crianças, sendo três delas autistas e uma não autista ${ }^{5}$. Foram explorados vídeos de desenhos animados sobre alimentação saudável, realizadas receitas pelas crianças (assessoradas por seus pais), criados modelos de alimentos saudáveis e feita caça ao tesouro (brincadeira em que cada estudante buscou alimentos saudáveis em sua própria casa). As crianças foram desafiadas a experimentar ao menos um alimento saudável até o último encontro da oficina. Todas elas participaram das propostas e demonstraram ter gostado das mesmas, afirmando que tentariam comer alguma comida saudável a partir de então.

As outras três oficinas pedagógicas versaram sobre conteúdos de astronomia. A oficina Céu de dia e a noite teve participação de duas crianças, de dois e três anos, embora tenham se inscrito quatro crianças. Apesar disso, as duas crianças participantes interagiram e realizaram todas as atividades propostas, que envolveram a montagem de duas caixas para relação de figuras - uma caixa do céu de dia e uma caixa do céu de noite -, além de desenhos animados e atividades de desenho, recorte e colagem.

Apesar de a oficina Uma pequena viagem pelos planetas do sistema solar ter a inscrição de cinco jovens, ela contou com a participação de dois jovens autistas e um neurotípico, com idades entre 13 e 16 anos. Essa proposta foi desenvolvida a partir de webconferência apoiada por slides e vídeos. Os vídeos trataram de conteúdos diversificados: um deles com explicações sobre gravidade, outro apresentou sons dos planetas, um terceiro vídeo trouxe reflexões sobre como seria se um planeta desaparecesse do sistema solar e um quarto vídeo versou sobre a idade dos planetas, pelo qual os jovens puderam calcular a idade de cada planeta do sistema solar.

Na mesma oficina, com o aplicativo Sky Map nos celulares, foi possível observar imagens de cada planeta. Outras atividades foram realizadas envolvendo números pares e ímpares (para formação de palavras relacionadas a planetas), quiz e jogo on-line. Houve participação dos jovens em todas as atividades e a mãe de um deles mencionou que seu filho não conseguiu realizar o desafio envolvendo números, apesar de ter gostado da oficina.

A oficina Os astros visíveis no céu foi trabalhada com quatro crianças, com idades entre quatro e cinco anos. Ela foi a única proposta concretizada em dois dias consecutivos, posto que a atividade assíncrona foi feita pelas crianças antes do primeiro encontro.

O relato dessa oficina e reflexões sobre o processo foram publicados em artigo científico na Revista Cenas Educacionais (SANTOS et al., 2021). Disponível em: https://www.revistas.uneb.br/index.php/cenaseducacionais/ article/view/11822. Acesso em: 9 nov. 2011. 
As atividades voltaram-se à representação de processos envolvidos nos movimentos de rotação e translação do Planeta Terra, escalas de tempo (dia e de noite) e unidades de medida de tempo (dia, semana, mês e ano). Para isso, foram usados modelos didáticos, objetos domésticos (bola, lanterna, almofadas), slides e vídeos. Segundo as organizadoras da oficina, houve empolgação das crianças na brincadeira, quando elas deviam abaixar e levantar para responder sim ou não, respectivamente, a perguntas propostas pelo grupo. Também, apesar de terem demonstrado aprender sobre movimentos da Terra, foi observado que as crianças não entenderam o conteúdo medidas do tempo.

Após a concretização das oficinas, os licenciandos foram orientados, por meio de webconferência e leitura de texto, sobre como analisar os conteúdos dos dados acerca da aprendizagem dos estudantes participantes. Após a organização e interpretação dos mesmos, houve orientações sobre a escrita dos relatos das experiências nas oficinas pedagógicas, trazendo resultados da aprendizagem dos participantes. Esses relatos de experiência foram apresentados em espaço na plataforma AVA para posterior publicação por meio de revisão e contribuições dos orientadores para além da disciplina núcleo temático.

Os conteúdos dos relatos de experiência foram divulgados na última reunião geral do núcleo temático por meio de apresentação oral remota, via webconferência. Nesse espaço, todos os participantes do núcleo temático apresentaram suas produções no decorrer da disciplina.

\section{Percepções dos Licenciandos Sobre Autismo}

No início da análise dos dados começou-se a verificar que os licenciandos tinham conhecimentos prévios acerca do transtorno, o que levou à aplicação de formulário com questão complementar aos mesmos. Essa ação foi necessária, de modo a conhecer se antes de ingressarem na disciplina NT esses licenciandos já tinham participado de algum tipo de atividade que fornecesse informações sobre o TEA. O Quadro 4 apresenta informações sobre esses estudantes e suas experiências e conhecimentos anteriores sobre autismo.

Quadro 4 - Informações sobre participantes do estudo

\begin{tabular}{|c|c|c|c|c|}
\hline Identificação & $\begin{array}{c}\text { Idade } \\
\text { (anos) }\end{array}$ & Profissão & $\begin{array}{c}\text { Experiência } \\
\text { com pessoa } \\
\text { autista }\end{array}$ & $\begin{array}{c}\text { Participação anterior em atividade(s) } \\
\text { sobre autismo e/ou conhecimentos } \\
\text { acerca do tema }\end{array}$ \\
\hline L1 & 31 & Outra & Não & $\begin{array}{c}\text { Acompanhava vídeos sobre } \\
\text { autismo, segue pessoas autistas } \\
\text { em redes sociais, assistia filmes e } \\
\text { documentários sobre o tema. }\end{array}$ \\
\hline L2 & 33 & Outra & Nenhuma & $\begin{array}{c}\text { Assistiu série de reportagens sobre } \\
\text { autismo em programa televisivo. }\end{array}$ \\
\hline L3 & 23 & Estudante & $\begin{array}{c}\text { Possui amigo } \\
\text { autista. }\end{array}$ & $\begin{array}{c}\text { Descobriu ter primo autista e passou } \\
\text { a pesquisar o assunto na internet. }\end{array}$ \\
\hline L4 & 33 & Professora & $\begin{array}{c}\text { Conhece } \\
\text { duas pessoas } \\
\text { autistas, foi } \\
\text { professora de } \\
\text { uma delas. }\end{array}$ & $\begin{array}{r}\text { Participou de minicurso na escola em } \\
\text { que trabalha. }\end{array}$ \\
\hline
\end{tabular}




\begin{tabular}{|c|c|c|c|c|}
\hline L5 & 25 & Estudante & Não & $\begin{array}{l}\text { Participou de palestras e pesquisou } \\
\text { sobre o tema em redes sociais e sites } \\
\text { da internet. }\end{array}$ \\
\hline L6 & 28 & Estudante & Nenhuma & $\begin{array}{l}\text { Por meio de relatos de amigos que } \\
\text { possuem familiares autistas. }\end{array}$ \\
\hline L7 & 25 & Estudante & Não & $\begin{array}{l}\text { Por meio de série televisiva que } \\
\text { retrata vida de jovem autista. }\end{array}$ \\
\hline L8 & 37 & Outra & Nenhuma & $\begin{array}{c}\text { Após amiga descobrir que seu filho é } \\
\text { autista, começou a pesquisar sobre o } \\
\text { assunto. }\end{array}$ \\
\hline L9 & 25 & Estudante & Não & $\begin{array}{l}\text { Observando comportamentos de } \\
\text { filhos autistas de pessoas próximas. }\end{array}$ \\
\hline L10 & 31 & Estudante & $\begin{array}{l}\text { Conhece, } \\
\text { mas não tem } \\
\text { aproximação. }\end{array}$ & $\begin{array}{l}\text { Vídeos no Youtube e pesquisas em } \\
\text { sites da internet. }\end{array}$ \\
\hline L11 & 20 & Estudante & Não & $\begin{array}{c}\text { Canais do Youtube e vídeos do } \\
\text { Instagram. }\end{array}$ \\
\hline L12 & 24 & Estudante & Não & Vídeos do Youtube e Instagram. \\
\hline L13 & 31 & Estudante & $\begin{array}{l}\text { Conhece, } \\
\text { mas não tem } \\
\text { aproximação. }\end{array}$ & $\begin{array}{l}\text { Sabia que acometia mais meninos } \\
\text { que meninas. }\end{array}$ \\
\hline
\end{tabular}

Fonte: Arquivos dos autores, 2021.

Assim, conforme o Quadro apresentado, apesar de a maioria dos participantes não terem experiências com pessoas autistas, todos já tinham algum conhecimento sobre o transtorno, seja por busca pessoal pelo tema, seja por meio de conversas com amigos, redes sociais e programas televisivos. De acordo com L2, "Meu primeiro contato com o autismo foi em uma série de reportagens na TV [...], pesquisei um pouco mais sobre esse tema, [...] acompanhei também um pouco no canal no YouTube". Para L11, "Em relação ao autismo, já havia assistido alguns vídeos no YouTube e Instagram que falavam sobre as características, diagnóstico e tratamento de crianças nessa condição". Ainda que as estudantes tenham afirmado a existência de diversos canais de informação acerca do assunto, ainda há carência de discussões sobre autismo nos cursos de Graduação.

O estudo de Oliveira, Angelo e Streiechen (2020), com licenciandos em Letras, coadunou com essa verificação, posto que eles indicaram que a maior parte do conhecimento prévio de seus 22 acadêmicos participantes provieram de estudos particulares movidos por interesses pessoais. Segundo os mesmos, professores em formação inicial estão recebendo pouca informação sobre a inclusão escolar de pessoas autistas, além de outras deficiências (OLIVEIRA; ANGELO; STREIECHEN, 2020).

A primeira pergunta dos questionários aplicados no início e ao final do Núcleo Temático aos licenciandos, sondou a sua definição de autismo. As respostas dadas a essa questão, nos dois questionários, mostraram que os mesmos já tinham conhecimentos prévios relevantes sobre a condição, apesar de haver alguns entendimentos estereotipados, como pode ser observado no Quadro 5. 
Quadro 5 - Definição de autismo

\begin{tabular}{|c|c|c|c|}
\hline Subcategorias do pré-teste & Respondente & Subcategorias do pós-teste & Respondente \\
\hline $\begin{array}{c}\text { Transtorno/distúrbio/ } \\
\text { condição mental }\end{array}$ & $\begin{array}{c}\mathrm{L} 1, \mathrm{~L} 3, \mathrm{~L} 4, \mathrm{~L} 5, \\
\mathrm{~L} 6, \mathrm{~L} 7, \mathrm{~L} 9, \mathrm{~L} 13\end{array}$ & $\begin{array}{c}\text { Transtorno/Síndrome/ } \\
\text { Condição de saúde }\end{array}$ & $\begin{array}{c}\mathrm{L1}, \mathrm{L} 2, \mathrm{~L} 5, \mathrm{~L} 6, \mathrm{~L} 7, \\
\mathrm{~L} 8, \mathrm{~L} 9, \mathrm{~L} 10, \mathrm{~L} 11, \\
\mathrm{~L} 12, \mathrm{~L} 13\end{array}$ \\
\hline $\begin{array}{c}\text { Atraso/alteração cognitiva/ } \\
\text { característica }\end{array}$ & $\mathrm{L} 2, \mathrm{~L} 10, \mathrm{~L} 12$ & Deficiência & $\mathrm{L} 4$ \\
\hline $\begin{array}{c}\text { Pessoas que vivem em seu } \\
\text { mundo }\end{array}$ & $\mathrm{L} 8$ & $\begin{array}{c}\text { Pessoas carinhosas e } \\
\text { participativas }\end{array}$ & $\mathrm{L} 3$ \\
\hline
\end{tabular}

Fonte: Arquivo dos autores, 2021.

A maioria dos licenciandos $(n=7)$ inicialmente entendia o autismo como um transtorno, distúrbio ou condição mental. Apesar de muitos demonstrarem insegurança em tratar sobre o tema, as referidas palavras foram apresentadas em suas definições, como afirmou a estudante L1: "Não consigo descrever; na verdade não tenho conhecimento sobre a TEA, mas acredito que este transtorno seja uma condição mental que torna especiais as pessoas que o têm". O mesmo foi verificado no relato de L4: "De forma muito leiga, posso dizer que uma pessoa com esse transtorno tem muita dificuldade de se socializar, comunicação, linguagem". Independente da insegurança demonstrada nas respostas, ou de provir da definição médica do TEA, a mesma coaduna com o Manual Estatístico e Diagnóstico de Transtorno Mentais (DSM), da Associação de Psiquiatria Americana (APA), em que o TEA é classificado no grupo de transtornos do neurodesenvolvimento, que engloba "o transtorno autista (autismo), o transtorno de Asperger, o transtorno desintegrativo da infância, o transtorno de Rett e o transtorno global do desenvolvimento sem outra especificação do DSM-IV" (APA, 2014, p. 853).

Quatro licenciandos identificaram o TEA como um tipo de atraso, uma alteração cognitiva ou uma característica do indivíduo. Assim como no caso anterior, muitos deles também apresentaram falta de segurança em suas afirmações, como L10: "Com o pouco conhecimento que tenho sobre o autismo, definiria o mesmo como sendo um atraso nas habilidades, linguagens e comunicação".

Apenas L8 assim abordou o TEA: "são pessoas que preferem viver isoladas, no seu mundo". Isso demonstrou uma ideia equivocada, uma vez que muitos autistas querem interagir com outras pessoas, mas têm dificuldades por terem problemas para esta interação. Muitas vezes eles querem interagir, mas possuem pouca reciprocidade a tentativas de contato, pois, geralmente, não correspondem a iniciativas com sorrisos ou olhares, além de terem dificuldades de compreender pensamentos, intenções e sentimentos de outras pessoas (ROGERS; DAWSON, 2014, WILLIANS; WRIGHT, 2008).

Também, o estudo de Oliveira, Angelo e Streiechen (2020) mostrou que, ainda que mínimos, a maioria dos acadêmicos em letras tinham conhecimentos anteriores sobre TEA, principalmente voltados a características básicas do transtorno. Observou-se, porém, alguns entendimentos equivocados, baseados em ideias do senso comum. Esse fato ainda foi verificado por Ponce e Abrão (2019), que observaram o "desamparo pedagógico" das professoras entrevistadas, afirmando não terem formação sobre o tema; "como fator mais desestimulante no exercício de sua atividade, vem de encontro 
ao conhecimento superficial que estas possuem acerca do autismo, já permeado por contradições e ideias do senso comum" (p. 350). Isso foi confirmado por L8, uma professora deste estudo, que também mencionou que autistas "vivem em seu mundo", ideia estigmatizada socialmente (PONCE; ABRÃO, 2019).

Ao final da disciplina houve modificações nas respostas dos licenciandos (Quadro 6). Quase todos ( $n=11$ ) passaram a entender que o TEA é Transtorno, Síndrome, Condição de saúde que acomete o indivíduo. Ainda que essa seja uma concepção médica do autismo, com base em características do transtorno, considera-se que esse conhecimento seja importante, ainda que se tenha a consciência de que a pessoa autista é mais que o transtorno. Conforme Ravet (2017), destarte a preocupação com a rotulação do indivíduo, o conhecimento do transtorno de modo a efetivar a inclusão dessas pessoas é menos prejudicial que a ignorância sobre o tema.

Ainda, os licenciandos que relacionaram autismo à deficiência (L4) e a "pessoas participativas e carinhosas"(L3), trouxeram um entendimento mais amplo, mais integral das pessoas com TEA, dado que, em outras respostas, evidenciaram conhecer tecnicamente sobre o transtorno, conforme Quadros 5 e 6.

Quadro 6-Características do TEA

\begin{tabular}{|c|c|c|c|}
\hline Subcategorias do pré-teste & Respondente & Subcategorias do pós-teste & Respondente \\
\hline $\begin{array}{c}\text { Problemas de } \\
\text { comunicação/linguagem, } \\
\text { de interação social e de } \\
\text { comportamento (tríade) }\end{array}$ & $\begin{array}{c}\mathrm{L} 5, \mathrm{~L} 6, \mathrm{~L} 7, \mathrm{~L} \text {,9, } \\
\mathrm{L} 10\end{array}$ & $\begin{array}{c}\text { Problemas de comunicação/ } \\
\text { linguagem, de interação social } \\
\text { e de comportamento (tríade) }\end{array}$ & $\mathrm{L} 1$ \\
\hline $\begin{array}{c}\text { Tríade e mais algumas } \\
\text { características }\end{array}$ & $\begin{array}{c}\mathrm{L} 1, \mathrm{~L} 13, \mathrm{~L} 11, \\
\mathrm{~L} 13\end{array}$ & $\begin{array}{c}\text { Tríade e mais algumas } \\
\text { características }\end{array}$ & $\begin{array}{c}\mathrm{L} 5, \mathrm{~L} 6, \mathrm{~L} 8, \mathrm{~L} 9, \\
\mathrm{~L} 10, \mathrm{~L} 12\end{array}$ \\
\hline Pessoa especial & $\mathrm{L} 1, \mathrm{~L} 2$ & Pessoa com deficiência & $\mathrm{L} 4$ \\
\hline Duas características & $\mathrm{L} 3, \mathrm{~L} 8$ & $\begin{array}{c}\text { Pessoa com dificuldades de } \\
\text { interação social }\end{array}$ & $\mathrm{L} 7$ \\
\hline Depende de cada indivíduo & $\mathrm{L4}$ & $\begin{array}{c}\text { Pessoas agitadas que precisam } \\
\text { de cuidados }\end{array}$ & $\mathrm{L} 2$ \\
\hline & - & Pessoas prestativas & $\mathrm{L} 3$ \\
\hline & - & Pessoa com mundo particular & $\mathrm{L} 11$ \\
\hline
\end{tabular}

Fonte: Arquivo dos autores, 2021.

Acerca das características do transtorno apresentadas no Quadro 6, foi observada uma diversificação das percepções entre as respostas prévias e as posteriores. A maioria dos respondentes entendiam o autismo conforme seus atributos, depois surgiram percepções diferentes, algumas, inclusive, estereotipadas: "Pessoa com mundo particular" (L11) e "Pessoas agitadas que precisam de cuidados" (L2). Também surgiram algumas percepções que demonstraram entendimento mais integral dos indivíduos com TEA, tais como "Pessoas prestativas" (L3) e "Pessoa com deficiência" (L4). Esses dois últimos licenciados reafirmaram o que responderam em questão anterior. 
Assim, apesar de a maioria dos participantes demonstrarem conhecer características do TEA ou apresentarem ideias mais voltadas a entendimento integral da pessoa autista, dois licenciandos mantiveram percepções equivocadas das condições, apenas caracterizando-a segundo estereótipos sociais (L2, L11).

No estudo de Souza et al. (2019) envolvendo as oficinas pedagógicas sobre autismo, observou-se aumento no número de acertos relativos ao TEA, entre pré e pós-teste. Apesar, contudo, de haver, como neste caso, ampliação de conhecimentos sobre o TEA no que trata do transtorno, é preciso considerar a permanência de ideias estereotipadas sobre pessoas autistas.

Talvez o entendimento de L11 de que o indivíduo autista consiste em "Uma pessoa que tem o seu próprio mundo particular", diga respeito às especificidades dessas pessoas, dado que essa estudante mostrou entender o autismo como um transtorno neurológico. Ainda, talvez a afirmação de que autistas "São pessoas agitadas, que necessitam de atenção, carinho, cuidado, e para se fazer entender necessita de referências"(L2), tenha se referido à observação dessa licencianda no decorrer de sua oficina pedagógica realizada com crianças autistas pequenas. Nesses casos seria preciso a verificação dessas questões pelos professores formadores antes do final do NT e do levantamento dessas reflexões, possibilitando a ressignificação de ideias. A dinâmica formativa da disciplina, entretanto, além das dificuldades do ensino remoto quando a equipe se encontrava em processo de adaptação a novas formas de ensinar e aprender, impossibilitou essa constatação.

\section{CONSIDERAÇÕES FINAIS}

Relatou-se a experiência de professores formadores e estudantes de Licenciatura em ciências da natureza no desenvolvimento de oficinas pedagógicas interdisciplinares e inclusivas de modo remoto, junto a crianças e jovens autistas e não autistas, além da possibilidade de mudanças nas percepções desses licenciandos sobre autismo. Verificou-se que a experiência possibilitou o desenvolvimento de cinco oficinas pedagógicas que buscaram incluir os participantes, tendo ou não deficiência, com base em seus interesses, potencialidades e dificuldades. Esses espaços propiciaram experiências educacionais aos participantes, além de valiosas vivências formativas aos organizadores, envolvendo o desenvolvimento de conhecimentos e habilidades da docência e sobre a inclusão de pessoas com TEA.

Observou-se ampliação de percepções da maioria dos licenciandos quanto a conhecimentos básicos do transtorno e suas características. Notou-se, entretanto, prevalência de percepções estereotipadas em duas licenciandas. Ainda, porém, que a disciplina Núcleo Temático Inclusivo no Ensino de Ciências pudesse ter levado à ressignificação dessas ideias, o dinamismo da mesma, junto a adaptação ao ensino remoto, impossibilitou esse processo.

Este artigo contribuiu com estudos sobre formação inclusiva de estudantes de Licenciatura, apontando proposta formativa interessante à formação para inclusão de pessoas autistas. Em decorrência da limitação do estudo de caso, todavia, é preciso 
realizar outras experiências desse tipo para comparação de ideias e para possibilitar a criação de estratégias para superação de dificuldades encontradas na proposta, cenário propício à formação inclusiva dos sujeitos envolvidos.

\section{REFERÊNCIAS}

APA. American Psychiatric Association. Diagnostic and statistical manual of mental disorders. 5. ed. Washington (DC): American Psychiatric Association, 2013.

APA. American Psychiatric Association. Manual diagnóstico e estatístico de transtornos mentais: DSM-V. Porto Alegre: Artmed, 2014.

BARDIN, L. Análise de conteúdo. Lisboa: Edições 70, 1977.

BRASIL. Resolução no 510, de 07 de abril de 2016. Dispõe sobre as normas aplicáveis a pesquisas em Ciências Humanas e Sociais. Diário Oficial [da] República Federativa do Brasil, Brasília, DF, 24 maio 2016. BRASIL. Ministério da Educação. Base Nacional Comum Curricular - BNCC. Brasília: MEC, 2018.

DILLON, G.; UNDERWOOD, J.; FREEMANTLE, L. J. Autism and the U.K. secondary school experience. Focus on Autism and Other Developmental Disabilities, 2014. p. 1-10.

GOMES, C. Gr. S. Desempenhos emergentes na aquisição de leitura funcional de crianças com transtorno do espectro autístico. 2007. Dissertação (Mestrado em Educação Especial) - Universidade Federal de São Carlos, São Carlos, SP, 2007.

MATIAS, H. B. R.; PROBST, M. A criança com transtorno do espectro autista, a escola e o professor: algumas reflexões. Revista Profissão Docente, Uberaba-MG, v. 18, n. 38, p. 158-170, jan./jun. 2018.

MORAES, R. Análise de conteúdo. Revista Educação, Porto Alegre, v. 22, n. 37, p. 7-32, 1999.

MOREIRA, M. A. Metodologias de pesquisa em ensino. São Paulo: Editora Livraria da Física, 2011.

OLIVEIRA, D. G. de; ANGELO, C. M. P.; STREIECHEN, Eliziane Manosso. Transtorno do espectro autista e formação docente: perspectivas de alunos do curso de letras. Teoria e Prática da Educação, v. 23, n. 3, p. 77-95, set./dez. 2020.

PONCE, J. O.; ABRÃO, J. L. F. Autismo e inclusão no ensino regular: o olhar dos professores sobre esse processo. Estilos da Clínica, v. 24, n. 2, p. 342-357, 2019.

RAVET, J. R. But how do I teach them?': Autism \& Initial Teacher Education (ITE). International Journal of Inclusive Education, 2017.

ROGERS, S. J.; DAWSON, G. Intervenção precoce em crianças com autismo: Modelo Denver para a promoção da linguagem, da aprendizagem e da socialização. Lisboa: Lidel Edições Técnicas, 2014.

SANTOS, L. L. N.; LEÃO, M. F.; AGAPITO, F. M. Atendimento a estudantes com autismo em um município de Mato Grosso: com a palavra os profissionais da educação. Pesquisa em Foco, Uema, v. 23, p. 118-141, 2018.

SANTOS, F. B.; LIMA, G. B.; SACRAMENTO, I. S. S.; SHAW, G. S. L. O caso da oficina pedagógica uma proposta de alimentação saudável e o ensino de ciências para crianças autistas e não autistas. Cenas Educacionais, Caetité, Bahia, v. 9, n.e11822, p. 1-22, 2021.

SHAW, G. S. L. Núcleo temático inclusivo para construção de conhecimentos de licenciandos em ciências da natureza sobre o Transtorno do Espectro Autista. Atos de Pesquisa em Educação, Furb, v. 16, p. 1-23, 2021.

SOUZA, L. M. R.; GOMES, M. L. C. ; SILVA, J. A. ; SANTOS-CARVALHO, L. H. Z.; MARTONE, M. C. C. ; CARMO, J. S. Oficinas sobre transtorno do espectro autista para pais, cuidadores e profissionais: análise de uma experiência. Revista Educação Especial, v. 32, p. 8, 2019.

VIGOTSKY, L. S. A formação social da mente: o desenvolvimento dos processos psicológicos superiores. Trad. José Cipolla Neto, Luís Silveira Menna Barreto, Solange Castro Afeche. São Paulo: Martins Fontes, 2007.

WILLIANS, C.; WRIGHT, B. Convivendo com autismo e Síndrome de Asperger: estratégias e práticas para pais profissionais. São Paulo: M. Books Editora, 2008.

WING, L. The relationship between Asperger's syndrome and Kanners's autism. In: U. Frith (ed.). Autism and Asperger syndrome. Cambridge: Cambridge University Press, 1991. p. 93-121.

ZAFEIRIOU D. I.; VERVERI A.; VARGIAMI E. Childhood autism and associated comorbidities. Brain Development, v. 29, n. 5, p. 257-272, 2007. 